\title{
Caracterización de manantiales del departamento Ancasti en la provincia de Catamarca (Argentina)*
}

\section{Assessment of Springs in the Ancasti Department in the Catamarca Province (Argentina)}

\section{Caractérisation de sources d'eau de la région d'Ancasti dans la province de Catamarca (Argentine)}

\author{
Pablo E. Demin**, Laura Cano***, Ornella Castro****
}

Recibido: 2015-01-13 // Aprobado: 2015-03-20 // Disponible en linea: 2015-06-30

Como citar este artículo: Demin, P. E., Cano, L. y Castro, O. (2015). Caracterización de manantiales del departamento Ancasti en la provincia de Catamarca (Argentina). Ambiente y Desarrollo, 19(37), 23-32. http://dx.doi.org/10.11144/Javeriana.ayd19-37.cmda doi:10.11144/Javeriana.ayd19-37.cmda

\begin{abstract}
Resumen
Las poblaciones de la provincia de Catamarca, Argentina no tienen acceso al agua $\mathrm{O}$ el acceso es muy precario. Entre estas poblaciones se encuentran las de El Huayco, El Arbolito y El Puesto Nuevo, en el departamento Ancasti, donde cada familia y una escuela de la zona poseen su propia vertiente. En estos lugares se realizaron obras de captación de agua, a fin de que cada familia y la escuela tengan disponibilidad de este recurso. Con el objetivo de conocer la calidad del agua de abastecimiento de estas comunidades, se realizó un análisis del muestreo del agua en ocho manantiales. Los resultados obtenidos son en general aceptables, excepto en tres manantiales en los que se observa presencia de coliformes (Enterobacter sp.) y pseudomonas.
\end{abstract}

Palabras clave: calidad del agua; vertientes; Catamarca

Este artículo surge del proyecto de investigación Provisión de agua a localidades del departamento Ancasti, Provincia de Catamarca, financiado por el Ministerio de Desarrollo Social de La Nación (Argentina) y desarrollado por el Programa Prohuerta.

** Ingeniero agrónomo, máster en Riego y Drenaje, investigador del Instituto Nacional de Tecnología, Estación Experimental Agropecuaria Catamarca, Ruta 33- Km 4,5. Valle Viejo, Catamarca, Argentina. Correo electrónico: demin.pablo@inta.gob.ar

*** Ingeniera agrónoma, investigadora del Instituto Nacional de Tecnología, Estación Experimental Agropecuaria Catamarca, Ruta 33- Km 4,5. Valle Viejo, Catamarca, Argentina. Correo electrónico: cano.laura@inta.gob.ar

**** Ingeniera agrónoma, investigadora del Instituto Nacional de Tecnología, Estación Experimental Agropecuaria Catamarca, Ruta 33- Km 4,5. Valle Viejo, Catamarca, Argentina. Correo electrónico: castro.ornella@inta.gob.ar 


\begin{abstract}
The towns of the Catamarca province in Argentina do not have access to water, or have precarious access. Among these towns we can find El Huyaco, El Arbolito, and Puesto Nuevo, in the Ancasti department, where every family and a local school have their own watershed. Water collection works were performed in these places, so every family and the school could have access to this resource. In order to know the quality of the water provided to these communities, we performed an analysis of water samples from eight springs. The obtained results are acceptable, in general terms, with the exception of the samples from three springs, in which coliforms (Enterobacter sp.) and pseudomonas can be seen.
\end{abstract}

Keywords: water quality; watershed; Catamarca

\title{
Résumé
}

Les peuples de la province de Catamarca, Argentine n'ont pas d'accès à l'eau ou l'accès est précaire. Parmi ces communautés on trouve celles du Huayco, Arbolito et Puesto Nuevo dans la région d'Ancasti, où chaque famille et une école de la zone ont ses propres sources d'eau. Dans ces endroits on a réalisé des travaux de captage d'eau, pour que chaque famille et l'école aient disponibilité de cette ressource. Avec l'objectif de connaître la qualité de l'eau et l'approvisionnement aux communautés, on a réalisé une analyse de prélèvements d'eau dans huit sources. Les résultats obtenus sont en générale acceptables, à différence de trois sources dans lesquels on a observé la présence de coliformes (Enterobacter sp.) y pseudomonas.

Mots-clés: qualité de l'eau; sources; Catamarca 


\section{Introducción}

La provincia de Catamarca está ubicada al noroeste de la República Argentina, entre los $25^{\circ} 12^{\prime}$ y $30^{\circ} 04^{\prime}$ de latitud sur y entre los 69 $03^{\prime}$ y $64^{\circ} 58^{\prime}$ de longitud oeste, aproximadamente. La mayor parte de la provincia está cubierta por montańas y se divide en tres zonas diferenciadas (este, centro y oeste), el clima es árido y semiárido (Lobo et al., 2007).

En la región este de la provincia se encuentra, entre otros, el departamento Ancasti, a $90 \mathrm{~km}$ de la ciudad capital San Fernando del Valle de Catamarca, a $870 \mathrm{msnm}$. Limita al norte con el departamento de El Alto, al este con La Paz, al oeste con Capayán y al noroeste con Valle Viejo. Su clima es árido, de sierras y bolsones, con intensas heladas. En algunas localidades de este departamento se encuentran familias congregadas en pequeños parajes de distribución aislada y dedicadas a la pequeña producción pecuaria, desarrollando actividades de cría en base pastoril de ganado mayor y menor.

En esta zona existen manantiales (vertientes), con agua relativamente disponible todo el año, que habitualmente constituyen la principal fuente de abastecimiento de agua (figura 1). Sin embargo, por mucho tiempo existió un acceso al agua en forma precaria, es decir, los pobladores recorrían distancias relativamente grandes hasta la fuente más cercana para recolectar el agua con baldes y trasladarlos hasta la vivienda. Esta fue la única forma de garantizarse el agua para bebida, uso doméstico y uso pecuario. Cabe aclarar que no se realizaba ningún tipo de tratamiento que permitiera el uso de un agua segura para el consumo humano. A esta situación se suma el que en las inmediaciones de varios manantiales, el ganado tiene acceso al agua, pudiendo contaminarla.

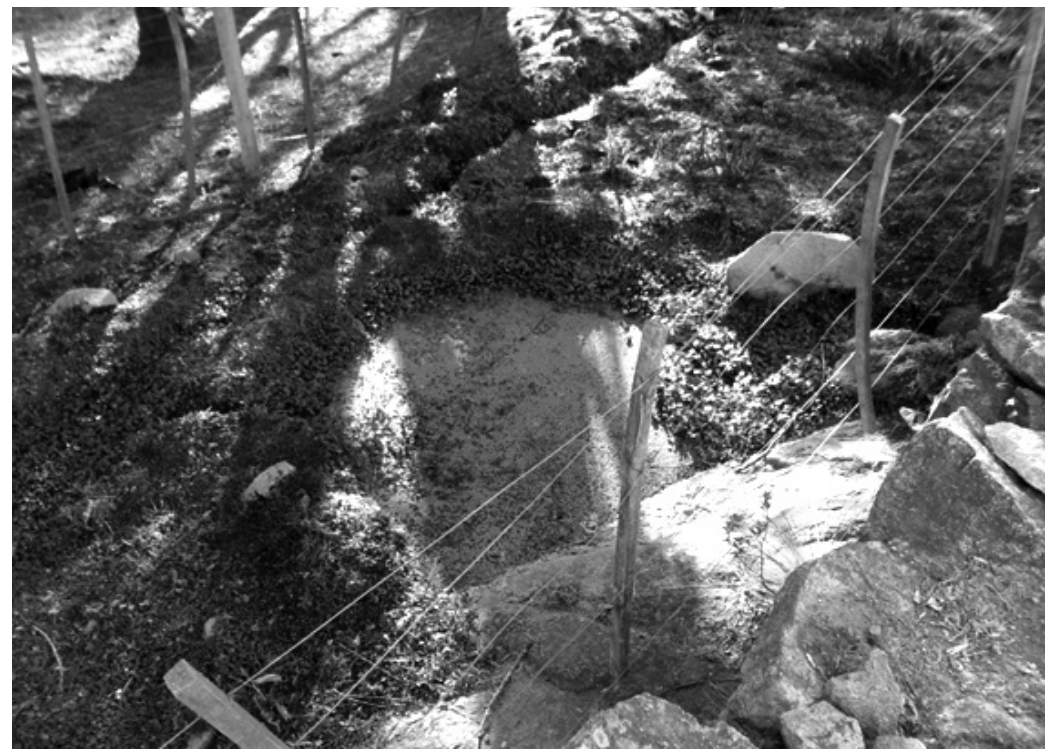

Figura 1. Manantial

Fuente: Ornella Castro

Durante el año 2012-2013 se realizaron obras de captación, conducción y almacenamiento de agua de vertientes en este lugar (figuras 2 y 3). Si bien se mejoró el acceso al agua de los pobladores de la zona, es necesario todavía hacer obras de tratamiento del agua (por ejemplo, filtrado y/o cloración) para alcanzar un agua segura para los pobladores. A fin de poder formular recomendaciones para implementar las medidas de manejo que contribuyan a mejorar la potabilidad del agua, en esta investigación se realizó una caracterización preliminar de la calidad del agua que corresponde a los manantiales de El Puesto Nuevo y El Arbolito y de la escuela de El Huayco. 


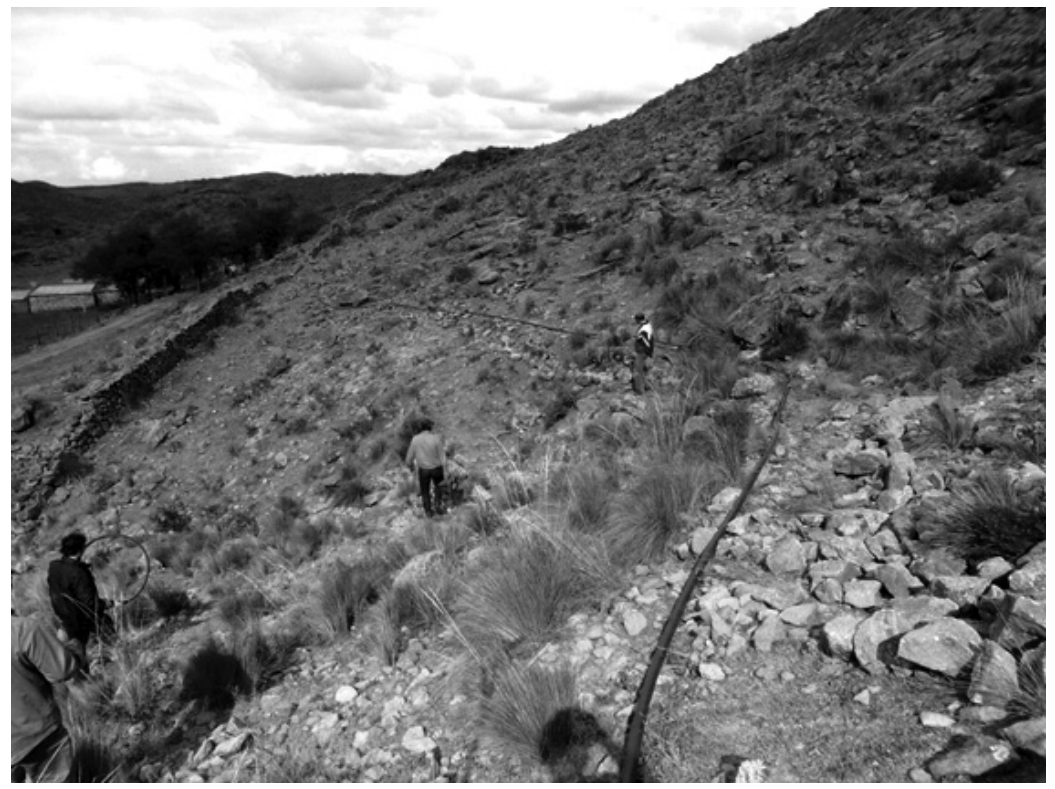

Figura 2. Conducción de agua por tubería

Fuente: Pablo Demin

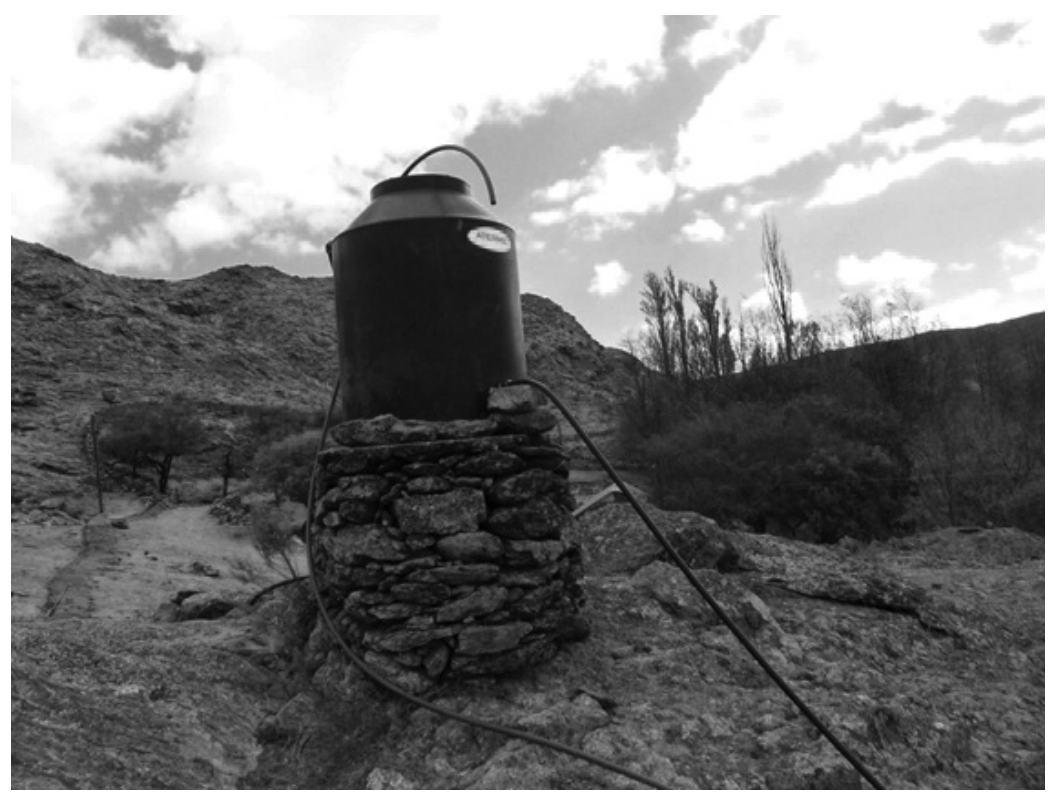

Figura 3. Tanque de almacenamiento de agua

Fuente: Pablo Demin

El objetivo de este trabajo fue realizar la caracterización inicial físico-química y bacteriológica del agua de manantiales del departamento Ancasti en la provincia de Catamarca (República Argentina), a fin de orientar las medidas de manejo para el abastecimiento de agua segura a la población. 


\section{Metodología}

El trabajo se inició con el muestreo de agua en los ocho manantiales que corresponden a los puntos de muestreo. Todos los manantiales están ubicados en los parajes de El Huayco, El Arbolito y El Puesto Nuevo, en el departamento Ancasti. En las figuras 4, 5, 6 y en la tabla 1 se presenta la ubicación de estos lugares de muestreo. Cabe aclarar que en algunas situaciones estos manantiales forman arroyos, en ese caso se extrajo una muestra de estos últimos.

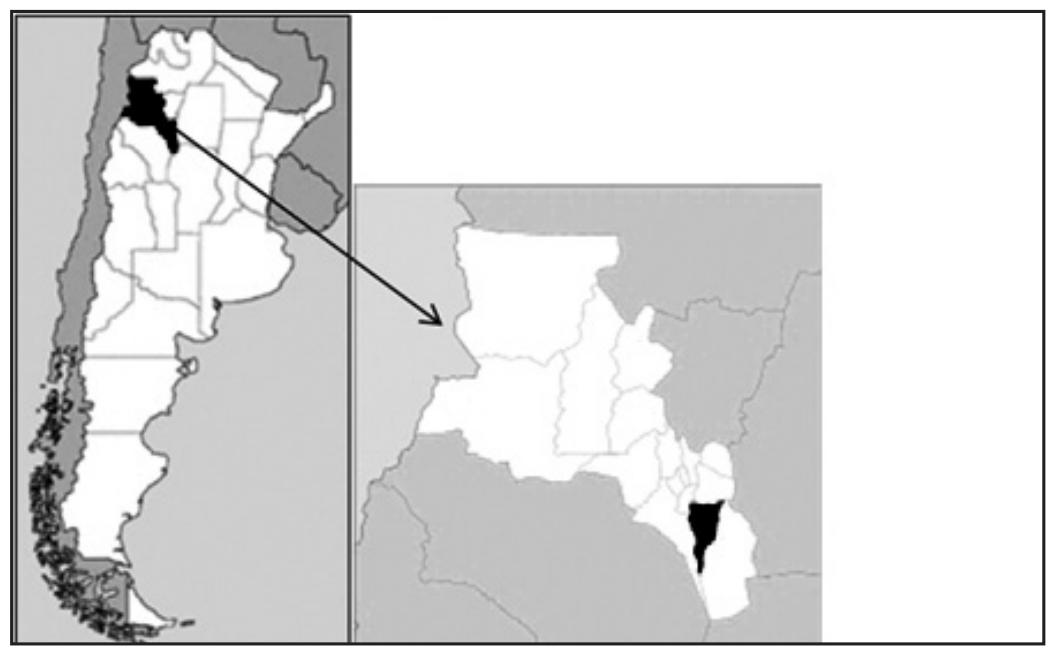

Figura 4. Ubicación del departamento Ancasti en la provincia de Catamarca, República Argentina

Fuente: www.wikipedia.org

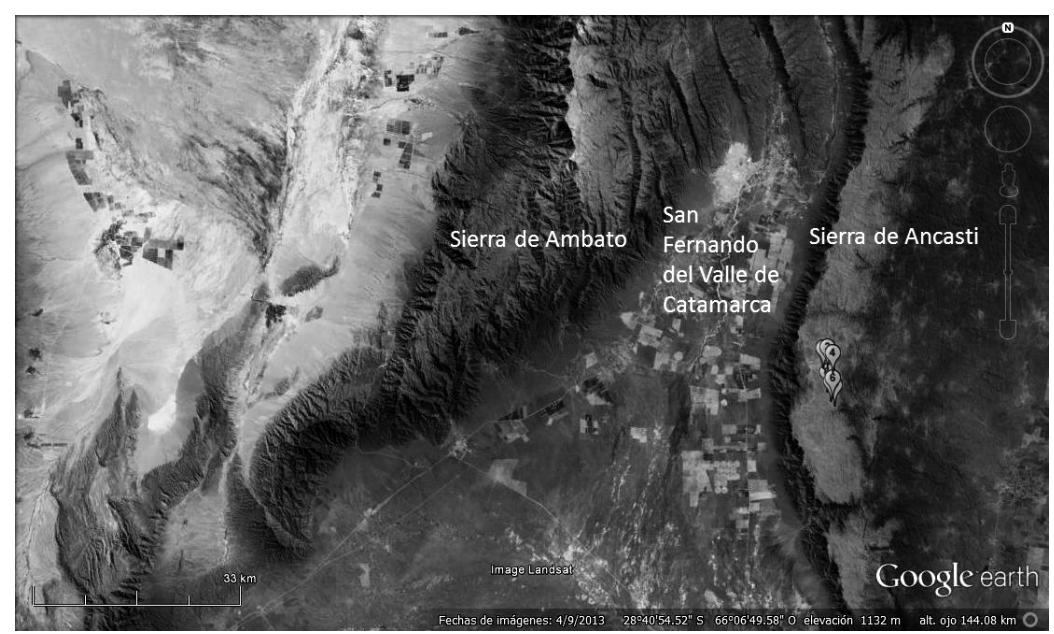

Figura 5. Ubicación del trabajo (sitios de muestreo) realizado en el departamento Ancasti en la provincia de Catamarca, Argentina

Fuente: Google Earth (2014) 


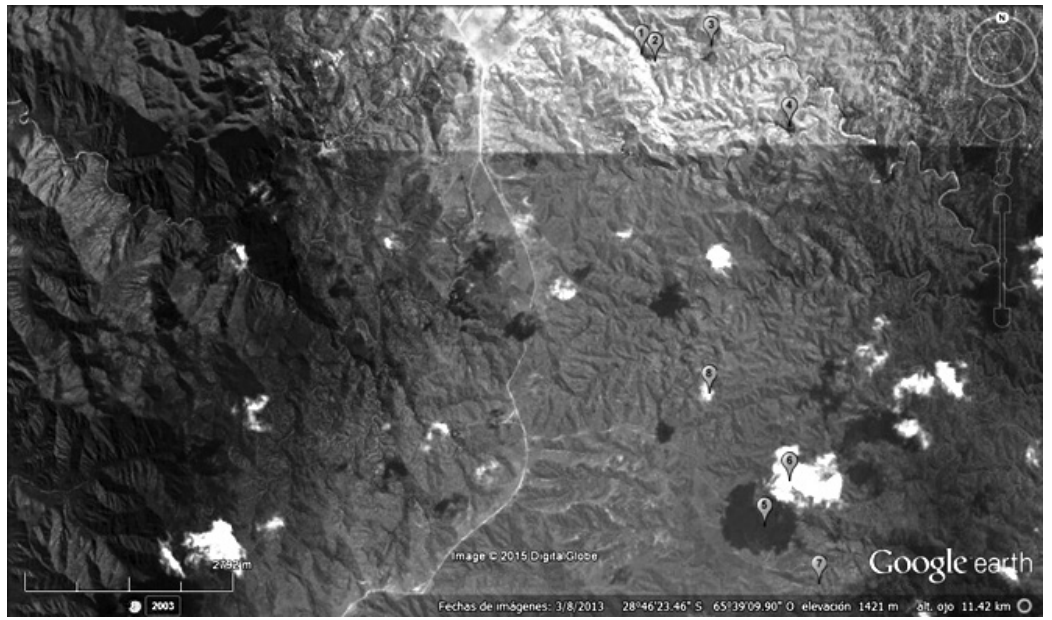

Figura 6. Imagen satelital de ubicación de los sitios de muestreo en el departamento Ancasti en la provincia de Catamarca, Argentina

Fuente: Google Earth (2014)

Tabla 1.

Ubicación de los puntos de muestreo

\begin{tabular}{|c|c|c|c|c|c|}
\hline & \multicolumn{3}{|c|}{ Ubicación } & \multirow{2}{*}{$\begin{array}{l}\text { Fecha de } \\
\text { muestreo }\end{array}$} & \multirow{2}{*}{$\begin{array}{l}\text { Tipo de } \\
\text { manantial }\end{array}$} \\
\hline Puesto & $\begin{array}{l}\text { Punto de } \\
\text { muestreo }\end{array}$ & Latitud & Longitud & & \\
\hline \multirow{3}{*}{ El Huayco } & 1 & $28^{\circ} 44^{\prime} 50,22^{\prime \prime} \mathrm{S}$ & $65^{\circ} 38^{\prime} 21,07^{\prime \prime} \mathrm{O}$ & $23-04-13$ & manantial \\
\hline & 2 & $28^{\circ} 44^{\prime} 53^{\prime \prime S}$ & $65^{\circ} 58^{\prime} 15.53^{\prime \prime O}$ & $23-04-13$ & manantial \\
\hline & 3 & $28^{\circ} 44^{\prime} 46.89^{\prime \prime S} \mathrm{~S}$ & $65^{\circ} 37^{\prime} 51.88^{\prime \prime O}$ & $22-11-13$ & manantial \\
\hline Pues to Nuevo & 4 & $28^{\circ} 45^{\prime} 16,23^{\prime \prime} \mathrm{S}$ & $65^{\circ} 37^{\prime} 19.24^{\prime \prime O}$ & $22-11-13$ & arroyo \\
\hline \multirow{4}{*}{ El Arbolito } & 5 & $28^{\circ} 47^{\prime} 42.02^{\prime \prime S}$ & $65^{\circ} 37^{\prime} 30.89^{\prime \prime O}$ & $12-09-13$ & manantial \\
\hline & 6 & $28^{\circ} 47^{\prime} 26^{\prime \prime S} \mathrm{~S}$ & $65^{\circ} 37^{\prime} 20,10^{\prime \prime} \mathrm{O}$ & $12-09-13$ & arroyo \\
\hline & 7 & $28^{\circ} 48^{\prime} 3,08^{\prime \prime} \mathrm{S}$ & $65^{\circ} 37^{\prime} 8,58^{\prime \prime} \mathrm{O}$ & $12-09-13$ & manantial \\
\hline & 8 & $28^{\circ} 46^{\prime} 53,87^{\prime \prime} \mathrm{S}$ & $65^{\circ} 37^{\prime} 53,61^{\prime \prime} \mathrm{O}$ & $12-09-13$ & manantial \\
\hline
\end{tabular}

Fuente: elaboración de Pablo Demin

El muestreo consistió en la extracción de una muestra de agua en cada uno de los puntos de muestreo, a fin de hacerle análisis físico-químico, y en la extracción de una muestra en tres puntos para análisis bacteriológico. Este muestreo se llevó a cabo desde el 23 de abril hasta el 19 de septiembre del 2013, período anterior al de las lluvias (verano). Cabe aclarar que se muestrearon todos los manantiales (y/u arroyos que estos forman) en distintas estaciones del año, por lo que el efecto de la variación de la temperatura, las precipitaciones y/u otros factores climáticos podrían estar reflejados en la concentración/dilución de las sales. El muestreo y la conservación de las muestras de agua se efectuaron según el protocolo elaborado por Basán et al. (2009). En el centro del manantial se obtuvieron las muestras de agua a una altura inferior al pelo de agua, pero a su vez alejada del fondo del río. De la misma manera, se realizó el muestreo en los arroyos. Las muestras se conservaron en botellas plásticas de $1500 \mathrm{~cm}^{3}$ y se mantuvieron refrigeradas hasta llegar al laboratorio en el mismo día de la extracción. Asimismo, se realizó la obtención de muestras destinadas a análisis bacteriológicos, aunque en este caso se utilizaron envases esterilizados. 
En cuanto a las mediciones en laboratorio, se tomó como referencia a Álvarez et al. (2011), aunque estos autores realizaron mediciones en campo durante el muestreo y una mayor cantidad de determinaciones en laboratorio. Las determinaciones efectuadas en este trabajo fueron: conductividad eléctrica ( $\mathrm{CE}$ ) expresada en decisiemens por metro $(\mathrm{dS} / \mathrm{m}), \mathrm{pH}$, aniones (sulfatos, cloruros, nitratos, nitritos, fluoruro) y cationes (calcio, sodio, magnesio, amonio), expresados en $\mathrm{mg} / \mathrm{L}$, RAs, sólidos totales disueltos (STD), dureza total (DT) y alcalinidad total (АT); estos dos últimos parámetros expresados en $\mathrm{mg} / \mathrm{L}$ de carbonato de calcio $\left(\mathrm{CaCO}_{3}\right)$. En el análisis bacteriológico se determinaron bacterias mesófilas, coliformes (Enterobacter sp.), Escherichia coli y Pseudomonas aeruginosa.

Cabe aclarar que si bien los puntos de muestreo 1 y 2 tienen el mismo origen, es decir, provienen del mismo manantial, en el punto 1 se extrajo la muestra de agua directamente del manantial, a diferencia del punto 2 , donde el agua estuvo primero en un tanque desarenador y luego en un tanque de almacenamiento. Esto permite comparar la calidad del agua sin tratar del manantial respecto del agua cuyas impurezas fueron decantadas.

\section{Resultados}

Los valores obtenidos a partir del muestreo efectuado en los distintos puntos y su posterior análisis en laboratorio, sin realizar mediciones in situ, se detallan en las tablas 2 y 3.

Tabla 2.

Análisis físico-químico

\begin{tabular}{|c|c|c|c|c|c|c|c|c|c|}
\hline Punto de muesteo & 1 & 2 & 3 & 4 & 5 & 6 & 7 & 8 & \multirow[b]{2}{*}{ (N/P) No P resenta } \\
\hline \multirow[t]{2}{*}{ Color } & $\mathrm{N} / \mathrm{P}$ & $\mathrm{N} / \mathrm{P}$ & $\mathrm{N} / \mathrm{P}$ & $\mathrm{N} / \mathrm{P}$ & $\mathrm{N} / \mathrm{P}$ & $\mathrm{N} / \mathrm{P}$ & $\mathrm{N} / \mathrm{P}$ & $N / P$ & \\
\hline & $\mathrm{N} / \mathrm{P}$ & $\mathrm{N} / \mathrm{P}$ & $\mathrm{N} / \mathrm{P}$ & $\mathrm{N} / \mathrm{P}$ & $\mathrm{N} / \mathrm{P}$ & $N / P$ & $N / P$ & $N / P$ & \multirow{2}{*}{ (P) Presencia leve } \\
\hline \multirow[t]{2}{*}{ Turbiedad } & $N / P$ & $N / P$ & P/LEVE & $\mathrm{N} / \mathrm{P}$ & $N / P$ & $N / P$ & $N / P$ & $\mathrm{~N} / \mathrm{P}$ & \\
\hline & 7,4 & 7,58 & 6,93 & 7,32 & 7,06 & 7,75 & 7,46 & 7,76 & \multirow{2}{*}{$\begin{array}{l}\left.{ }^{*}\right) 6,5-8,5 \\
\left.{ }^{*}\right) \max 1500\end{array}$} \\
\hline $\mathrm{SDT}(\mathrm{mg} / \mathrm{l})$ & 118 & 135 & 254 & 269 & 224 & 264 & 287 & 192 & \\
\hline \multirow{2}{*}{$\begin{array}{l}\mathrm{DT}\left(\mathrm{mgCaCO_{3 } / l )}\right. \\
\mathrm{AT}(\mathrm{mgCaC} \mathrm{O} / \mathrm{l})\end{array}$} & 75 & 81 & 148 & 110 & 108 & 156 & 48 & 78 & \multirow[t]{2}{*}{$\left.{ }^{*}\right) \max 400$} \\
\hline & 81,5 & 98 & 194 & 199 & 167 & 66 & 245 & 92 & \\
\hline \multirow{2}{*}{$\begin{array}{c}\mathrm{CE}(\mathrm{dS} / \mathrm{cm}) \\
\mathrm{Ca}^{+}(\mathrm{mg} / \mathrm{l})\end{array}$} & 0,1844 & 0,211 & 0,397 & 0,42 & 0,35 & 0,413 & 0,448 & &, 3 \\
\hline & 22 & 26 & 45 & 34 & 32 & 50 & 14 & 22 & - \\
\hline $\mathrm{Mg}^{+}(\mathrm{mg} / \mathrm{l})$ & 5,1 & 4 & 9 & 6 & 7 & 8 & 3 & 5 & \multirow[t]{2}{*}{-} \\
\hline $\mathrm{Na}^{+}(\mathrm{mg} / \mathrm{l})$ & 12 & 14 & 30 & 55 & 42 & 37 & 107 & 15 & \\
\hline $\mathrm{SO}^{-}(\mathrm{mg} / \mathrm{l})$ & 15 & 16 & 29 & 40 & 19 & 188 & 24 & 12 & (*) $\max 400$ \\
\hline $\mathrm{Cr}^{-}(\mathrm{mg} / \mathrm{l})$ & 2,5 & 2 & 6 & 8 & 7 & $<1$ & 7 & $<1$ & (*) $\max 350$ \\
\hline $\mathrm{NO3}^{-}(\mathrm{mg} / \mathrm{l})$ & 4,5 & 6 & $<1$ & $<1$ & 9 & $<1$ & 1 & $<1$ & $\left.{ }^{*}\right) \max 45$ \\
\hline $\mathrm{NO}_{2}^{-}(\mathrm{mg} / \mathrm{l})$ & $<0,03$ & $<0,03$ & $<0,03$ & $<0,03$ & $<0,03$ & $<0,03$ & $<0,03$ & $<0,03$ & $\left.{ }^{*}\right) \max 0,1$ \\
\hline $\mathrm{NH}_{4}^{+}(\mathrm{mg} / \mathrm{l})$ & 0,07 & $<0,05$ & $<0,05$ & $<0,05$ & 0,09 & $<0,05$ & $<0,05$ & $<0,05$ & \multirow{4}{*}{$\begin{array}{l}-\left(^{*}\right) \max 0,2 \\
-{ }^{(*)} \max 0,05 \\
-\left({ }^{*}\right) 0,7-1,2 \max 2\end{array}$} \\
\hline As $(\mathrm{mg} / \mathrm{l})$ & 0,01 & $<0,01$ & 0,01 & 0,01 & $<0,01$ & $<0,01$ & $<0,01$ & $<0,01$ & \\
\hline \multirow{2}{*}{$\mathrm{F}^{-}(\mathrm{mg} / \mathrm{l})$} & 0,1 & 0,51 & 0,68 & 0,75 & 0,82 & 0,56 & 1,71 & 0,62 & \\
\hline & \multicolumn{8}{|c|}{$\begin{array}{l}{ }^{*} \text { Nalores de referencia C ódiqo Alimen. Arq. Art } 982 \\
()^{*} \text { Nalores de referencia Obras Sa nitarias de la Nación }\end{array}$} & \\
\hline
\end{tabular}

Tabla 3.

Análisis bacteriológico

\begin{tabular}{|c|c|c|c|c|}
\hline & & & & \multirow[b]{3}{*}{$\leq 500 \cup \mathrm{FC} / \mathrm{mL}$} \\
\hline Punto de mues treo & 2 & 3 & 4 & \\
\hline Mesófilas (UFC/mL.) & $>500$ & 96 & 76 & \\
\hline \multirow{4}{*}{$\begin{array}{r}\text { Coliformes (UFC } / 100 \mathrm{~mL} \text { ) } \\
\text { Escherichia coli }(100 \mathrm{~m} . \mathrm{L}) \\
\text { Peudomonas aeruginosa }(100 \mathrm{~m} . \mathrm{L})\end{array}$} & 0 & $20^{*}$ & 0 & \multirow{4}{*}{$\begin{array}{l}\leq 3 \mathrm{UFC} / 100 \mathrm{~mL} . \\
\text { Aus encia } / 100 \mathrm{~mL} \text {. } \\
\text { Aus encia } / 100 \mathrm{~mL} \text {. }\end{array}$} \\
\hline & AUSENCIA & AUSENCIA & AUSENCIA & \\
\hline & AUSENCIA & PRESENCIA & PRESENCIA & \\
\hline & & $\begin{array}{l}\text { nterobacter sp. } \\
\text { ncia Cód.Alim. }\end{array}$ & & \\
\hline
\end{tabular}

Fuente: elaboración de Pablo Demin 


\section{Discusión}

Como se puede observar en la tabla 2, el pH del agua se encuentra entre 6,93 y 7,76 en los ocho puntos muestreados. Estos son valores normales, es decir, dentro de un rango permitido por el Código Alimentario Argentino (CAA) que indica valores aceptables de $\mathrm{pH}$ de 6 a 9 para el consumo humano.

La dureza del agua, que está en función de la concentración de $\mathrm{CaCO}_{3}$, expresada en $\mathrm{mg} / \mathrm{L}$ de $\mathrm{CaCO}_{3}$, es menor al valor máximo de $400 \mathrm{~g} / \mathrm{L}$ mencionado en el CAA. En los puntos 7 y 8 , el agua se considera suave (menor a $75 \mathrm{mg} / \mathrm{L}$ ), mientras que en el resto de los puntos se la considera poco dura (entre 75 y $150 \mathrm{mg} / \mathrm{L}$ ). En cuanto a los sólidos totales disueltos, los valores observados en todos los puntos de muestreo son menores al valor máximo establecido por el CAA de $1500 \mathrm{mg} / \mathrm{L}$. Con respecto a la alcalinidad total expresada en $\mathrm{CaCO}_{3}$, todas las muestras tienen valores menores a $1500 \mathrm{mg} / \mathrm{L}$, que es el valor máximo indicado por el CAA.

La conductividad eléctrica (CE) en todas las muestras se encuentra en valores con bajo contenido salino, según el valor máximo establecido por el caA de $2,3 \mathrm{dS} / \mathrm{m}$.

Los valores de CE son bajos en todos los puntos muestreados, aunque los puntos 4, 6 y 7 muestran valores algo mayores $(>0,4 \mathrm{dS} / \mathrm{m})$ que el resto.

De la tabla 2 se desprende también que, en general, la concentración de cationes y aniones es baja en todas las muestras. La muestra 6 tiene una concentración mayor de sulfatos $(188 \mathrm{mg} / \mathrm{l})$, pero inferior al límite que es de $500 \mathrm{mg} / \mathrm{L}$ para sulfatos, según el CAA.

Las concentraciones de nitratos, tomando como referencia el CAA, que establece un límite de hasta $45 \mathrm{mg} / \mathrm{L}$, en todos los casos se encuentran por debajo de este valor. Los iones nitrito y amonio, cuyos límites mencionados por el CAA son de hasta $0,10 \mathrm{mg} / \mathrm{L}$ para el nitrito y de $0,2 \mathrm{mg} / \mathrm{L}$ para el amonio, son bajos en todos los casos, es decir, no existen problemas de contaminación en sus respectivas épocas de muestreo.

La concentración de flúor en todos los casos es menor al límite máximo establecido por el cAA, que es de 2,0 mg/L, sin embargo, el punto 7 , en ese momento de muestro, mostró un valor algo mayor (1,71 $\mathrm{mg} / \mathrm{L}$ ), cercano al límite máximo.

El contenido de sodio, calcio y magnesio, cuyos límites según el CaA son de hasta 650, 160 y $98 \mathrm{mg} / \mathrm{L}$, respectivamente, es bajo en todos los puntos de muestreo. En la muestra 7 hay una concentración mayor de sodio $(107 \mathrm{mg} / \mathrm{L})$ que en las otras muestras, pero es inferior al límite. La concentración de arsénico, considerando el nivel máximo permitido por el CAA $(0,01 \mathrm{mg} / \mathrm{L})$ se encuentra por debajo de este límite.

Considerando la época de muestreo, que corresponde al período comprendido entre otońo y primavera, esto es, alejado de las precipitaciones estivales, el contenido de sales en estos lugares de muestreo es bajo en sus respectivas épocas de muestreo.

Desde el punto de vista bacteriológico, en sus correspondientes épocas de muestreo, la cantidad de bacterias mesófilas en todos los puntos muestreados es menor al límite del CAA de 500 unidades formadoras de colonias. Estos valores bajos difieren de lo que se esperaría, ya que en todos los manantiales y arroyos se halló una gran cantidad de materia orgánica vegetal durante el muestreo. La presencia de coliformes (Enterobacter sp.) es elevada en el punto 3, mientras que los otros lugares de muestreo no presentan coliformes. Ninguna muestra de agua revela presencia de la bacteria Escherichia coli, en tanto que con respecto a Pseudomonas aeruginosa, existe presencia en los puntos 3 y 4. Por lo tanto, según las épocas de muestro, se debe tener precaución con la fuente de contaminación del punto 3, ya que la contaminación por coliformes es de origen fecal y puede provenir de animales o del hombre, mientras que la presencia de Pseudomonas aeruginosa, si es de origen fecal, proviene del hombre.

Comparando la muestra de agua sin decantar del manantial con la muestra de agua decantada en tanque, del mismo manantial (puntos 1 y 2 , respectivamente), se puede apreciar un leve incremento del 
pH después de decantar el agua del manantial. Se puede observar también una pequeña menor cantidad de ión amonio del agua decantada respecto del agua sin decantar, y esto se acompaña de una leve mayor cantidad del ión nitrato en el agua decantada. Estas apreciaciones deben ser estudiadas con mayor profundad. En el resto de los cationes y aniones no se observan diferencias apreciables.

\section{Conclusiones}

- Las tareas de muestreo realizadas en los manantiales y arroyos que de la zona de El Huayco, El Arbolito y El Puesto Nuevo, en el departamento Ancasti, provincia de Catamarca, República Argentina, ha permitido obtener una caracterización preliminar de la calidad físico-química del agua.

- El conocimiento de las características hidrológicas (hidrometeorología, escurrimiento superficial y subterráneo, etc.) debería integrarse al análisis de los resultados obtenidos, para lograr la interpretación de los estos con un enfoque sistémico. Debe tenerse en cuenta que la calidad y la cantidad de agua son el resultado de los procesos de transformación de la entrada de agua al sistema hidrológico-ambiental que representa la cuenca.

- Si bien los valores obtenidos para aniones y cationes mayoritarios, $\mathrm{pH}$, conductividad eléctrica, etc., señalan que la calidad del agua se encuentra dentro de los límites establecidos en el CAA para las aguas de bebida, desde el punto de vista bacteriológico, al menos en dos puntos de muestreo, el agua no es apta para consumo en esas condiciones.

- A fin de mejorar el conocimiento de la calidad del agua de estos lugares de muestreo y poder definir índices que faciliten el monitoreo del recurso, se considera indispensable dar continuidad sistemática a estos muestreos, en otras estaciones del año, a lo largo de varios años, y complementar las tareas con la determinación en campo de, al menos, $\mathrm{pH}$, temperatura, conductividad eléctrica, oxígeno disuelto, Dво у DQO.

- Se recomienda realizar el inventario y la caracterización de todas las actividades que se realizan en zonas aguas arriba de los manantiales, a fin de formular recomendaciones que promuevan la protección de estas fuentes de abastecimiento.

- Se recomienda, asimismo, en los manantiales o arroyos que están desprotegidos implementar perímetros de protección, para evitar el acceso de animales que pudieran constituir agentes de contaminación potencial del agua, y que su abrevado sea en otro lugar.

- El filtro lento es la mejor opción para instalar en esta zona, aunque una medida de prevención inmediata para llevar a cabo en este lugar es hervir durante 5-10 minutos el agua destinada a bebida, lo cual elimina la totalidad de las bacterias. El agregado de cloro al agua no sería recomendado, puesto que el agua en este caso no es decantada ni filtrada y, por lo tanto, la cantidad de cloro que se debe agregar es alta, pudiendo alcanzar niveles tóxicos; además, la bacteria Pseudomonas aeruginosa es resistente al cloro y, en consecuencia, se necesitan también altas dosis de cloro. 


\section{Bibliografía}

Álvarez A., D’Elía, M., París, M., Fasciolo, G. y Barbazza, C. (2011). Evaluación de la contaminación de acuíferos producida por actividades de saneamiento y re-uso de efluentes en el norte de la provincia de Mendoza. Revista de la Facultad de Ciencias Agrarias de la Universidad Nacional de Cuyo, 43(1), 19-39.

Basán-Nickisch, M., Gallo-Mendoza, L., Rosas, D., Zamar, S., Ostinelli, M., Carreira, D., Tuchneider, O., Parías, M., Pérez, M. y D’Elía, M. (2009). Protocolo de muestreo, transporte y conservación de muestras de agua con fines múltiples (consumo humano, abrevado animal y riego). Argentina: Instituto Nacional de Tecnología Agropecuaria.

Bermejillo, A., Martí, L., Cónsoli, D., Salcedo, C., Llera, J., Valdés, A., Venier, M. y Troilo, S. (2012). Aptitud para riego del agua subterránea basada en la salinidad y sodicidad en las perforaciones realizadas entre 2004 y 2010 en los Oasis Norte y Centro de Mendoza. Revista FCA UN Cuyo, 44(2), 221-240.

Código Alimentario Nacional, Argentina (2010). Capítulo XII (pp. 982-1079).

Gobierno de la Provincia de Catamarca, Argentina (2011). Etisig Catamarca (Equipo de Trabajo Interinstitucional en Sistemas de Información Geográfica). Recuperado de www.atlas.catamarca.gov.ar

Google Earth (2006). Sitio web. Recuperado de http://earth.google.com

Lobo, P., Alves, J. y Varela, M. (2007). La hidrografía y el agua en Catamarca. Argentina: Secretaría del Agua y del Ambiente, Gobierno de Catamarca.

Wikipedia.org (s.f.) Mapa de la Provincia de Catamarca, República Argentina. Recuperado el 22 de mayo del 2015, de www. wikipedia.org 